\title{
The Impact of Perioperative Use of a Statin-Magnesium Combination on Opioid Consumption in Patients Who Underwent Cardiac Surgery: A Retrospective Study with Propensity-Score Matching
}

\author{
Cheol Lee ${ }^{1}$ and Cheol Hwan So ${ }^{2, *}$ \\ Departments of ${ }^{1}$ Anesthesiology and Pain Medicine, ${ }^{2}$ Pediatrics, Wonkwang University School of Medicine, Iksan, Korea
}

\begin{abstract}
Both statins and magnesium are associated with NMDA receptors and anti-inflammatory effect. Peripheral NMDA receptors are known to be involved in inflammationinduced pain. This study aimed to investigate the impact of perioperative use of a statinmagnesium combination on opioid consumption in patients who underwent cardiac surgery. This was a retrospective study of 542 patients who underwent cardiac surgery. The patients were divided into two groups according to statin use: the statin-magnesium group $(n=375)$ and the magnesium-only group $(n=167)$. Patients in the magnesium-only group received only perioperative magnesium, but no statins, to prevent atrial fibrillation following cardiac surgery. After propensity-score matching, $228 \mathrm{pa}$ tients ( $\mathrm{n}=114$ in each group) were analyzed to investigate opioid consumption, visual analogue scale (VAS) pain scores over a 72-h period, and pain outcomes according to the duration of statin treatment $(<1$ or $\geq 1 \mathrm{yr}$ ). The consumed opioid volume was significantly smaller in statin-magnesium group than the magnesium-only group, both before $(\mathrm{p}=0.010)$ and after matching $(\mathrm{p}=0.017)$. The statin-magnesium combination did not significantly reduce the VAS pain scores compared with magnesium alone. Although the statin-magnesium combination did not significantly reduce the pain intensity compared with magnesium alone, the combination therapy was effective in reducing opioid consumption after surgery.
\end{abstract}

Key Words: Narcotics; Pain Management; Anti-Arrhythmia Agents; Drug Interactions; Cardiac Surgical Procedures

This is an Open Access article distributed under the terms of the Creative Commons Attribution Non-Commercial License (http://creativecommons.org/licenses/by-nc/4.0) which permits unrestricted non-commercial use, distribution, and reproduction in any medium, provided the original work is properly cited.

\section{Article History:}

Received February 5, 2020

Revised February 14, 2020

Accepted February 24, 2020

\section{Corresponding Author:}

Cheol Hwan So

Department of Pediatrics, Wonkwang University School of Medicine, 895

Muwang-ro, Iksan 54538, Korea

Tel: $+82-63-859-1510$

Fax: +82-63-853-3670

E-mail: sopedoc@gmail.com

\section{INTRODUCTION}

The management of pain after cardiac surgery is crucial because inadequately controlled pain may become chronic, thereby delaying rehabilitation, prolonging treatment duration, and detrimentally affecting the patient's quality of life. Effective treatment of pain in patients undergoing cardiac surgery should be multidimensional. The most frequently recommended type of analgesia is multimodal (combined pharmacotherapy), involving the simultaneous use of a few analgesic agents with different mechanisms of action, but with common properties. ${ }^{1,2}$ Statins reduce the synthesis and increase the clearance of cholesterol, while decreasing triglyceride levels. Preclinical studies have shown that the anti-inflammatory effects of statins are as- sociated with reductions in C-reactive protein (CRP) and proinflammatory cytokine levels. ${ }^{3,4}$ To date, there have been very few clinical studies on the effects of statins on pain in the perioperative period. ${ }^{5} \mathrm{~A}$ few studies have reported that perioperative statin use is not effective for reducing postoperative pain and opioid consumption. ${ }^{6,7}$

Magnesium, which is a cofactor of all enzymes in phosphate-transfer reactions that utilize adenosine triphosphates as substrates, is a noncompetitive $N$-methyl-D-aspartate (NMDA) receptor antagonist that blocks ion channels in a voltage-dependent manner. ${ }^{8}$ Systemic administration of perioperative magnesium reduces postoperative pain and opioid consumption and is considered a strategy to mitigate postoperative pain in surgical patients. ${ }^{1,8,9}$

Both statins and magnesium are associated with NMDA 
receptors and have anti-inflammatory effects. Peripheral NMDA receptors are known to be involved in inflammation-induced pain. ${ }^{1,8,10}$ The effects of the combination of these two agents with similar properties but different mechanisms of action on pain outcomes are still unknown.

We hypothesized that because both statins and magnesium are associated with NMDA receptors and have anti-inflammatory effects, their combined therapy could reduce opioid consumption postoperatively. The aim of our study was to investigate the impact of the perioperative use of a statin-magnesium combination on opioid consumption, as the primary outcome, in patients who underwent cardiac surgery.

\section{MATERIALS AND METHODS}

\section{Study design}

In this retrospective cohort study, we evaluated the medical records of all consecutive patients who underwent cardiac surgery from January 1, 2013 through December 30, 2018. Ethical approval for this study (registration no. 201907-027-002) was provided by the relevant institutional review board in August 2019.

\section{Patient selection}

Patients aged $>19$ years, with normal sinus rhythm, who underwent elective cardiac surgery (coronary artery bypass graft [CABG] surgery, valve surgery, or CABG plus valve surgery with cardiopulmonary bypass) under general anesthesia were considered eligible for inclusion in this study. We excluded patients with incomplete medical records. Patients with previous cardiac surgery, those receiving antiarrhythmic medications (digoxin, calcium channel blocker or beta-blocker, etc.) before surgery, and those undergoing off-pump coronary artery bypass or re-do surgery were also excluded. The data for the present study were collected from the medical records of eligible patients and included information about use of statins (atorvastatin, rosuvastatin, simvastatin, and others).

The patients were divided into two groups according to statin use: the statin-magnesium group $(n=375)$ and the magnesium-only group ( $\mathrm{n}=167$ ). Patients in the magnesiumonly group received only perioperative magnesium, but no statins, to prevent atrial fibrillation following cardiac surgery. The duration of statin treatment was divided into $<1$ and $\geq 1$ yr.

\section{Perioperative management of cardiac surgery per- formed under general anesthesia}

General anesthesia was induced with propofol and remifentanil and was maintained with sevoflurane. All patients underwent continuous cardiac monitoring, invasive blood pressure monitoring, and central vein pressure monitoring. Weaning from mechanical ventilation and catecholamine infusion, pulmonary artery catheter removal, and tracheal extubation in the intensive care unit were performed based on standard guidelines.
The standard of care for preventing atrial fibrillation postoperatively at our hospital was to administer magnesium sulfate and amiodarone. Magnesium was administered as a $30 \mathrm{mg} / \mathrm{kg}$ bolus followed by a $10 \mathrm{mg} / \mathrm{kg} / \mathrm{h}$ infusion over $24 \mathrm{~h}$, and amiodarone was administered as a $150 \mathrm{mg}$ bolus over $30 \mathrm{~min}$, followed by a $1 \mathrm{mg} / \mathrm{min}$ infusion over $6 \mathrm{~h}$, and a $0.5 \mathrm{mg} / \mathrm{min}$ infusion over $24 \mathrm{~h}$.

As routine care to reduce postoperative pain, each patient was administered analgesics using a patient-controlled analgesia (PCA) pump containing fentanyl (4000 $\mu \mathrm{g})$, ketorolac $(360 \mathrm{mg})$, and ramosetron $(0.9 \mathrm{mg})$ in a total volume of $500 \mathrm{~mL}$ saline. This device was set to deliver a background infusion of $2 \mathrm{~mL} / \mathrm{h}$ and bolus doses of $1 \mathrm{~mL}$ with a 10-min lockout period. Postoperative pain intensity was documented using a $100-\mathrm{mm}$ linear visual analogue scale (VAS). The VAS scores for pain at rest and during movement were measured at intervals of 24,48 , and $72 \mathrm{~h}$ after surgery.

\section{Primary outcome and secondary outcomes}

The primary outcome was opioid consumption based on the volume of PCA containing fentanyl (in milliliters) consumed over $72 \mathrm{~h}$ after surgery. The secondary outcomes included VAS pain scores over $72 \mathrm{~h}$, mechanical ventilation therapy, intensive care unit stay, pain outcomes according to the duration of statin treatment ( $<1$ or $\geq 1$ year), and incidence of postoperative atrial fibrillation.

\section{Statistical analysis}

Data are presented as mean \pm standard deviation or number (percentage) of patients. Continuous variables were analyzed using the independent $t$-test after performing the Shapiro-Wilk test for normality, whereas categorical variables were analyzed using the chi-square test or Fisher's exact test. Variables that differed between the two groups were subjected to propensity-score matching, which resulted in balanced variables between the statin-magnesium group and magnesium only groups at $\mathrm{p}>0.1$ and a standardized mean difference $(\mathrm{MD})<0.1$. Variables that could affect postoperative pain outcome were selected for propensity-score matching, and standardized MD of ordinal variables such as age and body mass index were calculated as nominal variables. No further adjustment was made after confirming a balance between the two groups as a criterion of $\mathrm{p}>0.1$ and $\mathrm{SMD}<0.1$. The association of statin-treatment duration with PCA volume and VAS pain intensity was analyzed using the Pearson's correlation test. Variables that differed between the two groups and that might affect the postoperative pain outcome were selected for PS matching. Statistical analysis was performed using SPSS version 18.0 (SPSS Inc., Chicago, IL, USA). p $<0.05$ was considered statistically significant.

\section{RESULTS}

Six hundred patients underwent cardiac surgery at this hospital from January 1, 2013 through December 30, 2018. 
Of these, 58 patients were excluded because of incomplete medical records, previous cardiac surgery, antiarrhythmic medication before surgery, and re-operation because of bleeding. Thus, 542 patients were included in this study. Propensity-score matching for baseline and clinical characteristics identified 228 paired patients in the two groups ( $\mathrm{n}=114$ per group).

The proportions of patients with diabetes mellitus, hypertension, smoking, peripheral arterial occlusive disease, and preoperative cerebrovascular accident were significantly higher in the magnesium-only group than in the statin-magnesium group before matching; however, these differences between the groups were not statistically significant after matching. The statin-magnesium combination treatment significantly increased the creatinine level at 1-day postoperatively after matching. The combination therapy also reduced the peak CRP level and the CRP level from the first to the third day postoperatively, before and after matching. Age, sex, body mass index, type of commonly prescribed statins, type and duration of cardiac surgery, mechanical ventilation, intensive care unit stay, creatinine level before surgery, and preoperative CRP levels were not significantly different between the two groups both before and after matching. Creatinine at 1 day after surgery was not significant between two groups before matching but creatinine was significantly increased in statin-magnesium group compared with magnesium only group $(\mathrm{p}=0.017)$ (Table 1).

The statin-magnesium group consumed significantly lower volumes of PCA containing fentanyl (in milliliters) over a 72-h period postoperatively than did the magnesium-only group, both before matching $(\mathrm{p}=0.010)$ and after matching $(\mathrm{p}=0.017)$. The VAS pain scores during movement in the first $24 \mathrm{~h}$ postoperatively were significantly lower in the statin-magnesium group than in the magnesium-only group, before matching. However, the VAS pain scores at 24,48 , and $72 \mathrm{~h}$ were not significantly different between the groups after matching (Table 2).

Patients with statin treatment $\geq 1$ yr consumed significantly lower PCA volumes than did those with statin treatment $<1$ year, both before $(\mathrm{p}=0.047)$ and after matching $(\mathrm{p}=0.047)$. The VAS pain scores over a $72-\mathrm{h}$ period in

TABLE 1. Patients' demographic data

\begin{tabular}{|c|c|c|c|c|c|c|}
\hline \multirow[b]{2}{*}{ Variables } & \multicolumn{3}{|c|}{ Before matching } & \multicolumn{3}{|c|}{ After matching } \\
\hline & $\begin{array}{l}\text { Magnesium-only } \\
\qquad(\mathrm{n}=375)\end{array}$ & $\begin{array}{l}\text { Statin-magnesium } \\
\quad(\mathrm{n}=167)\end{array}$ & p-value & $\begin{array}{c}\text { Magnesium-only } \\
(\mathrm{n}=114)\end{array}$ & $\begin{array}{l}\text { Statin-magnesium } \\
(\mathrm{n}=114)\end{array}$ & p-value \\
\hline Age (years) & $59.8 \pm 5.8$ & $59.7 \pm 5.8$ & $>0.05$ & $59.8 \pm 6.0$ & $59.4 \pm 5.9$ & $>0.05$ \\
\hline Sex (male/female) & $125 / 250$ & $53 / 114$ & $>0.05$ & $43 / 71$ & $31 / 83$ & $>0.05$ \\
\hline Body mass index $\left(\mathrm{kg} / \mathrm{m}^{2}\right)$ & $26.1 \pm 1.4$ & $26.1 \pm 1.5$ & $>0.05$ & $26.1 \pm 1.4$ & $26.0 \pm 1.5$ & $>0.05$ \\
\hline Diabetes mellitus & $66(17.6)$ & $44(26.3)$ & 0.019 & $19(16.7)$ & $29(25.4)$ & $>0.05$ \\
\hline Hypertension & $139(37.1)$ & $80(47.9)$ & 0.018 & $50(43.9)$ & $51(44.7)$ & $>0.05$ \\
\hline Smoking & $107(28.5)$ & $65(38.9)$ & 0.016 & $36(31.6)$ & $39(34.2)$ & $>0.05$ \\
\hline Peripheral arterial occlusive disease & $63(16.8)$ & $47(28.1)$ & 0.002 & $22(19.3)$ & $29(25.4)$ & $>0.05$ \\
\hline Preoperative cerebrovascular accident & $25(6.7)$ & $23(13.8)$ & 0.007 & $13(11.4)$ & $19(16.7)$ & $>0.05$ \\
\hline \multicolumn{7}{|l|}{ Commonly prescribed statins } \\
\hline Atorvastatin & & $63(37.7)$ & & & $40(35.1)$ & \\
\hline Rosuvastatin & & $48(28.7)$ & & & $33(28.9)$ & \\
\hline Fluvastatin & & $26(15.6)$ & & & $20(17.5)$ & \\
\hline Others & & $30(18.0)$ & & & $21(18.4)$ & \\
\hline \multicolumn{7}{|l|}{ Duration of statin treatment } \\
\hline$<1$ year & & $76(45.5)$ & & & $51(44.7)$ & \\
\hline$\geq 1$ year & & $91(54.5)$ & & & $63(55.3)$ & \\
\hline \multicolumn{7}{|l|}{ Type of cardiac surgery } \\
\hline Coronary bypass graft surgery & $131(34.9)$ & $57(34.1)$ & $>0.05$ & $40(35.1)$ & $39(34.2)$ & $>0.05$ \\
\hline Valve surgery & $122(32.5)$ & $55(32.9)$ & $>0.05$ & $37(32.5)$ & $38(33.3)$ & $>0.05$ \\
\hline Coronary bypass graft surgery+valve surgery & $122(32.5)$ & $55(32.9)$ & $>0.05$ & $37(32.5)$ & $37(32.5)$ & $>0.05$ \\
\hline Duration of cardiac surgery & $335.5 \pm 22.8$ & $333.4 \pm 26.3$ & $>0.05$ & $334.7 \pm 22.2$ & $332.6 \pm 25.2$ & $>0.05$ \\
\hline Mechanical ventilation (h) & $16.9 \pm 2.9$ & $17.0 \pm 2.7$ & $>0.05$ & $16.8 \pm 2.8$ & $17.0 \pm 2.7$ & $>0.05$ \\
\hline Intensive care unit stay $(\mathrm{h})$ & $62.3 \pm 7.5$ & $62.9 \pm 7.4$ & $>0.05$ & $61.8 \pm 7.5$ & $62.8 \pm 7.4$ & $>0.05$ \\
\hline Creatinine before surgery (mg/dL) & $0.69 \pm 0.12$ & $0.70 \pm 0.13$ & $>0.05$ & $0.69 \pm 0.12$ & $0.71 \pm 0.13$ & $>0.05$ \\
\hline Creatinine at 1 day after surgery $(\mathrm{mg} / \mathrm{dL})$ & $1.26 \pm 0.26$ & $1.28 \pm 0.21$ & $>0.05$ & $1.27 \pm 0.21$ & $1.29 \pm 0.21$ & 0.017 \\
\hline Preoperative CRP (mg/L) & $4.2 \pm 1.9$ & $4.2 \pm 1.8$ & $>0.05$ & $4.28 \pm 1.9$ & $4.22 \pm 1.8$ & $>0.05$ \\
\hline $\mathrm{CRP}$ at 1 day after surgery $(\mathrm{mg} / \mathrm{L})$ & $96.9 \pm 15.1$ & $92.2 \pm 13.2$ & 0.001 & $96.4 \pm 14.0$ & $92.4 \pm 13.0$ & 0.026 \\
\hline $\mathrm{CRP}$ at 3 day after surgery $(\mathrm{mg} / \mathrm{L})$ & $155.2 \pm 20.1$ & $149.0 \pm 20.0$ & 0.001 & $153.4 \pm 19.7$ & $146.5 \pm 19.1$ & 0.008 \\
\hline
\end{tabular}

Values are expressed as mean \pm standard deviation or numbers $(\%)$. CRP: C-reactive protein. 
TABLE 2. Pain intensity and opioid consumption in patients who underwent cardiac surgery

\begin{tabular}{|c|c|c|c|c|c|c|}
\hline \multirow[b]{2}{*}{ Variables } & \multicolumn{3}{|c|}{ Before matching } & \multicolumn{3}{|c|}{ After matching } \\
\hline & $\begin{array}{c}\text { Magnesium- } \\
\text { only } \\
(\mathrm{n}=375)\end{array}$ & $\begin{array}{c}\text { Statin- }^{-} \\
\text {magnesium } \\
(\mathrm{n}=167)\end{array}$ & $\mathrm{p}$-value & $\begin{array}{c}\text { Magnesium- } \\
\text { only } \\
(\mathrm{n}=114)\end{array}$ & $\begin{array}{c}\text { Statin- }^{-} \\
\text {magnesium } \\
(\mathrm{n}=114)\end{array}$ & $\mathrm{p}$-value \\
\hline $\begin{array}{l}\text { Volume of PCA containing fentanyl over } 72 \mathrm{~h} \\
\text { postoperatively }(\mathrm{mL})\end{array}$ & $341.3 \pm 31.3$ & $334.1 \pm 29.1$ & 0.010 & $341.8 \pm 30.8$ & $332.3 \pm 28.4$ & 0.017 \\
\hline VAS score at rest in the first $24 \mathrm{~h}$ postoperatively & $43.0 \pm 11.0$ & $41.1 \pm 11.3$ & $>0.05$ & $43.0 \pm 11.3$ & $40.7 \pm 11.3$ & $>0.05$ \\
\hline VAS score with movement in the first $24 \mathrm{~h}$ postoperatively & $62.6 \pm 10.9$ & $60.4 \pm 11.4$ & 0.035 & $62.5 \pm 11.3$ & $60.2 \pm 11.2$ & $>0.05$ \\
\hline VAS score at rest in the first $48 \mathrm{~h}$ postoperatively & $33.6 \pm 11.9$ & $33.4 \pm 12.0$ & $>0.05$ & $33.6 \pm 12.0$ & $33.3 \pm 12.0$ & $>0.05$ \\
\hline VAS score with movement in the first $48 \mathrm{~h}$ postoperatively & $51.7 \pm 10.0$ & $50.2 \pm 11.5$ & $>0.05$ & $51.7 \pm 10.4$ & $49.7 \pm 11.3$ & $>0.05$ \\
\hline VAS score at rest in the first $72 \mathrm{~h}$ postoperatively & $26.3 \pm 7.9$ & $26.0 \pm 7.8$ & $>0.05$ & $26.7 \pm 7.9$ & $25.9 \pm 7.5$ & $>0.05$ \\
\hline VAS score with movement in the first $72 \mathrm{~h}$ postoperatively & $39.3 \pm 10.5$ & $38.3 \pm 10.0$ & $>0.05$ & $39.6 \pm 10.8$ & $38.1 \pm 9.8$ & $>0.05$ \\
\hline
\end{tabular}

Values are expressed as mean \pm standard deviation.

PCA: patient-controlled analgesia, VAS: visual analogue scale.

TABLE 3. Pain intensity and opioid consumption according to the duration of statin treatment in patients who underwent cardiac surgery

\begin{tabular}{|c|c|c|c|c|c|c|}
\hline \multirow[b]{2}{*}{ Variables } & \multicolumn{3}{|c|}{ Before matching } & \multicolumn{3}{|c|}{ After matching } \\
\hline & $\begin{array}{l}\text { Duration } \\
<1 \text { year }\end{array}$ & $\begin{array}{l}\text { Duration } \\
\geq 1 \text { year }\end{array}$ & p-value & $\begin{array}{l}\text { Duration } \\
<1 \text { year }\end{array}$ & $\begin{array}{l}\text { Duration } \\
\geq 1 \text { year }\end{array}$ & p-value \\
\hline $\begin{array}{l}\text { Volume of PCA containing fentanyl over } 72 \mathrm{~h} \\
\text { postoperatively }(\mathrm{mL})\end{array}$ & $338.9 \pm 30.9$ & $329.9 \pm 27.0$ & 0.047 & $337.5 \pm 31.4$ & $327.0 \pm 24.1$ & 0.047 \\
\hline VAS score at rest in the first $24 \mathrm{~h}$ postoperatively & $43.1 \pm 11.9$ & $39.3 \pm 10.5$ & 0.031 & $42.8 \pm 11.9$ & $38.6 \pm 10.3$ & 0.046 \\
\hline VAS score with movement in the first $24 \mathrm{~h}$ postoperatively & $62.5 \pm 11.8$ & $58.7 \pm 10.7$ & 0.031 & $62.1 \pm 11.6$ & $58.2 \pm 10.5$ & $>0.05$ \\
\hline VAS score at rest in the first $48 \mathrm{~h}$ postoperatively & $35.6 \pm 12.2$ & $31.4 \pm 11.5$ & 0.025 & $35.4 \pm 12.0$ & $31.2 \pm 11.7$ & $>0.05$ \\
\hline VAS score with movement in the first $48 \mathrm{~h}$ postoperatively & $52.5 \pm 11.9$ & $48.2 \pm 10.8$ & 0.017 & $52.1 \pm 11.8$ & $49.4 \pm 10.4$ & $>0.05$ \\
\hline VAS score at rest in the first $72 \mathrm{~h}$ postoperatively & $27.4 \pm 8.5$ & $24.8 \pm 6.9$ & 0.029 & $27.2 \pm 8.2$ & $24.6 \pm 6.6$ & $>0.05$ \\
\hline VAS score with movement in the first $72 \mathrm{~h}$ postoperatively & $39.7 \pm 10.5$ & $37.1 \pm 9.4$ & 0.090 & $39.3 \pm 10.3$ & $36.8 \pm 9.1$ & $>0.05$ \\
\hline
\end{tabular}

Values are expressed as mean \pm standard deviation.

PCA: patient-controlled analgesia, VAS: visual analogue scale.

patients with statin treatment $\geq 1$ year were significantly lower $(\mathrm{p}<0.05)$ than those in patients with statin treatment $<1$ year, before matching. However, the duration of statin treatment had a weaker effect on reducing the VAS pain scores over the 72-h period after matching (Table 3 ). There was a statistically significantly negative, although weak, association of statin-treatment duration with opioid consumption over $72 \mathrm{~h}$ postoperatively $(\mathrm{r}=-0.154, \mathrm{p}=0.047)$, VAS score at rest $(\mathrm{r}=-0.167, \mathrm{p}=0.031)$, and VAS score with movement $(\mathrm{r}=-0.167, \mathrm{p}=0.031)$ in the first $24 \mathrm{~h}$ postoperatively. Additionally, the VAS score at rest $(\mathrm{r}=-0.173, \mathrm{p}=$ $0.025)$ and VAS score with movement $(r=-0.185, \mathrm{p}=0.017)$ in the first $48 \mathrm{~h}$ postoperatively, and the VAS score at rest $(\mathrm{r}=-0.169, \mathrm{p}=0.029)$ and VAS score with movement in the first $72 \mathrm{~h}$ postoperatively $(\mathrm{r}=-0.132, \mathrm{p}=0.09)$, were statistically significantly negatively, but weakly, correlated (Table 4).

The incidence of postoperative atrial fibrillation was not significant, regardless of the subtype of cardiac surgery before matching. After matching, the incidence of postoperative atrial fibrillation in the statin-magnesium group was significantly reduced compared with that in the magne-
TABLE 4. Association of statin-treatment duration with pain intensity and opioid consumption

\begin{tabular}{|c|c|c|}
\hline & \multicolumn{2}{|c|}{ Statin-treatment duration } \\
\hline & $\begin{array}{l}\text { Correlation } \\
\text { coefficient }\end{array}$ & p-value \\
\hline $\begin{array}{l}\text { Volume of PCA containing fentanyl } \\
\text { over } 72 \mathrm{~h} \text { postoperatively }(\mathrm{mL})\end{array}$ & -0.154 & 0.047 \\
\hline $\begin{array}{l}\text { VAS score at rest in the first } 24 \mathrm{~h} \\
\text { postoperatively }\end{array}$ & -0.167 & 0.031 \\
\hline $\begin{array}{l}\text { VAS score with movement in the } \\
\text { first } 24 \mathrm{~h} \text { postoperatively }\end{array}$ & -0.167 & 0.031 \\
\hline $\begin{array}{l}\text { VAS score at rest in the first } 48 \mathrm{~h} \\
\text { postoperatively }\end{array}$ & -0.173 & 0.025 \\
\hline $\begin{array}{l}\text { VAS score with movement in the } \\
\text { first } 48 \mathrm{~h} \text { postoperatively }\end{array}$ & -0.185 & 0.017 \\
\hline $\begin{array}{l}\text { VAS score at rest in the first } 72 \mathrm{~h} \\
\text { postoperatively }\end{array}$ & -0.169 & 0.029 \\
\hline $\begin{array}{l}\text { VAS score with movement in the } \\
\text { first } 72 \mathrm{~h} \text { postoperatively }\end{array}$ & -0.132 & 0.09 \\
\hline
\end{tabular}

PCA: patient-controlled analgesia, VAS: visual analogue scale. 
TABLE 5. Postoperative atrial fibrillation in patients according to type of cardiac surgery

\begin{tabular}{|c|c|c|c|c|c|c|}
\hline \multirow[b]{2}{*}{ Variables } & \multicolumn{3}{|c|}{ Before matching } & \multicolumn{3}{|c|}{ After matching } \\
\hline & $\begin{array}{l}\text { Magnesium-only } \\
\quad(\mathrm{n}=375)\end{array}$ & $\begin{array}{l}\text { Statin-magnesium } \\
\quad(\mathrm{n}=167)\end{array}$ & p-value & $\begin{array}{l}\text { Magnesium-only } \\
\quad(\mathrm{n}=114)\end{array}$ & $\begin{array}{l}\text { Statin-magnesium } \\
(\mathrm{n}=114)\end{array}$ & $\mathrm{p}$-value \\
\hline Postoperative atrial fibrillation & $64(17.1)$ & $23(13.8)$ & $>0.05$ & $28(24.6)$ & $14(12.3)$ & 0.017 \\
\hline Coronary bypass graft surgery & $27(20.6)$ & $6(10.5)$ & $>0.05$ & $12(30)$ & $2(5.1)$ & 0.004 \\
\hline Valve surgery & $18(14.8)$ & $9(16.4)$ & $>0.05$ & $8(21.6)$ & $7(18.4)$ & 0.729 \\
\hline Coronary bypass graft surgery+valve surgery & $19(15.6)$ & $8(14.5)$ & $>0.05$ & $8(21.6)$ & $5(13.5)$ & 0.359 \\
\hline
\end{tabular}

Values are expressed as numbers (\%).

sium-only group, but was reduced only in patients who underwent CABG surgery (Table 5).

\section{DISCUSSION}

The present study showed that the statin-magnesium group consumed significantly lower volumes of PCA containing fentanyl over a 72 -h period postoperatively than did the magnesium-only group, both before and after propensity-score matching. Before matching, the VAS pain scores with movement in the first $24 \mathrm{~h}$ postoperatively in patients who received the statin-magnesium combination was significantly lower than those in patients who received magnesium alone. After matching, the VAS pain scores at 24,48 , and $72 \mathrm{~h}$ were not significantly different between the two groups. The finding that the VAS pains scores at these time-points did not differ significantly between the groups might be attributable to the increased use of opioids by the magnesium-only group to reduce pain levels.

Preclinical and clinical studies have shown conflicting results regarding the effect of statins on pain outcomes. ${ }^{3,4,6,7}$ Animal studies have also suggested the beneficial effects of statins on pain, ${ }^{3,4}$ whereas clinical studies have indicated that statin treatment is not effective with respect to pain outcomes. ${ }^{6,7}$ At our hospital, magnesium has been administered as a standard of care for preventing postoperative atrial fibrillation. Some studies recommended magnesium administration as a strategy to mitigate postoperative pain in surgical patients. ${ }^{8,9}$ In the present study, the statin-magnesium combination significantly reduced pain compared with magnesium alone. Although statins and magnesium each have their own specific properties, both are associated with NMDA receptors and have an anti-inflammatory effect. ${ }^{1,8,10}$ Due to these common properties, the statin-magnesium combination shows a synergic effect compared with magnesium alone and may affect opioid consumption. Available clinical studies have reported the relationship between perioperative statin use and postoperative pain and opioid consumption. ${ }^{6,7}$ However, this study addresses the synergistic effect of a perioperative statin-magnesium combination on opioid consumption and pain intensity.

Since the results of studies on the effect of prolonged use of statins on pain and nociception are contradictory, the use of statins as analgesic adjuvants is not yet supported by evidence. ${ }^{6,7}$ In the present study, statin treatment $\geq 1 \mathrm{yr}$ resulted in significantly greater reduction in opioid consumption than did statin treatment $<1$ yr. However, correlation analysis showed a weakly negative relationship between the duration of statin treatment and opioid consumption or pain intensity. This result indicates that the effect of statin-treatment duration on opioid consumption and pain intensity remains controversial in terms of clinical implications.

Some studies have reported that there is an excess risk of acute kidney injury (AKI) within 2 years after statin initiation in high-potency statin users compared to lower-potency statin users, but only among patients without chronic kidney disease at baseline. ${ }^{11,12}$ However, other studies did not find a significant association between statin treatment and the risk of AKI or an excess risk of AKI with high-potency versus moderate-/low-potency regimens. ${ }^{13,14}$ The creatinine level after surgery in the present study did not differ significantly between the two groups, but the statin-magnesium group was higher than magnesium group after propensity-score matching. The most frequently reported risk factors for AKI after cardiac surgery include advanced age, female sex, New York Heart Association function class IV, reduced left ventricular ejection fraction or congestive heart failure, diabetes mellitus, poor glycemic control, peripheral vascular disease and chronic obstructive pulmonary disease, type of surgery, duration of CPB, blood transfusion, and hemolysis. ${ }^{15}$

According to the type of cardiac surgery in the present study, the incidence of postoperative atrial fibrillation in the statin-magnesium group was significantly lower in patients who underwent coronary artery bypass surgery than in those who underwent valve surgery or combined surgery. Some studies have reported that the beneficial effect of statins on postoperative atrial fibrillation was found only in patients who underwent CABG, but not in those who underwent valve surgery. Valvular diseases are mostly related to the aging process, due to calcification of the valves, but not to inflammatory responses or lipid deposition. ${ }^{16}$,

This study had some limitations. First, this retrospective study had a small sample size, which limits the generalization of the results. ${ }^{17}$ Studies with very large sample sizes may be needed to identify rare or controversial outcomes. 
Second, retrospective studies are known to have an inherent risk of bias if some key points are not addressed. Although we attempted to reduce this risk through propensity-score matching, some unmeasured or confounding factors may have influenced the results of the present study. Third, the observed effect of the statin-magnesium combination on opioid consumption and pain intensity in the present study might be difficult to apply to the effect of statin use only on pain outcomes. Finally, data on perioperative factors that could potentially affect the outcomes, such as total dose of opioids and anxiolytics, method of sedation, and postoperative nausea and vomiting, were not available for analysis.

In conclusion, the results of the present study demonstrate that the perioperative use of the statin-magnesium combination seems to reduce opioid consumption significantly postoperatively, which might be due to the synergistic reaction between statin and magnesium; however, it was unable to reduce pain intensity.

\section{ACKNOWLEDGEMENTS}

This study was supported by Wonkwang University 2020 and Wonkwang Medical Research Center.

We would like to thank Editage (www.editage.co.kr) for English language editing.

\section{CONFLICT OF INTEREST STATEMENT}

None declared.

\section{REFERENCES}

1. Zubrzycki M, Liebold A, Skrabal C, Reinelt H, Ziegler M, Perdas E, et al. Assessment and pathophysiology of pain in cardiac surgery. J Pain Res 2018;11:1599-611.

2. Bignami E, Castella A, Pota V, Saglietti F, Scognamiglio A, Trumello $\mathrm{C}$, et al. Perioperative pain management in cardiac surgery: a systematic review. Minerva Anestesiol 2018;84:488-503.

3. Ghaisas MM, Dandawate PR, Zawar SA, Ahire YS, Gandhi SP. Antioxidant, antinociceptive and anti-inflammatory activities of atorvastatin and rosuvastatin in various experimental models. Inflammopharmacology 2010;18:169-77.

4. Shi XQ, Lim TK, Lee S, Zhao YQ, Zhang J. Statins alleviate experimental nerve injury-induced neuropathic pain. Pain 2011; 152:1033-43.

5. Sneyd JR, Colvin LA, Columb MO, Nightingale T. Perioperative statins surgery and postoperative pain. Br J Anaesth 2017;119: 712-5.

6. Saasouh W, Leung S, Yilmaz HO, Koyuncu O, You J, Zimmerman
NM, et al. Are perioperative therapeutic doses of statins associated with postoperative pain and opioid consumption after hip surgery under spinal anaesthesia? Br J Anaesth 2017;119:80311.

7. Oh TK, Chang CB, Shin HJ, Han S, Do SH, Lee HJ, et al. Association between perioperative statin use and postoperative pain after total knee arthroplasty. Reg Anesth Pain Med 2019;44:221-6.

8. Ferasatkish R, Dabbagh A, Alavi M, Mollasadeghi G, Hydarpur E, Moghadam AA, et al. Effect of magnesium sulfate on extubation time and acute pain in coronary artery bypass surgery. Acta Anaesthesiol Scand 2008;52:1348-52.

9. El Mourad MB, Arafa SK. Effect of intravenous versus intraperitoneal magnesium sulfate on hemodynamic parameters and postoperative analgesia during laparoscopic sleeve gastrectomyA prospective randomized study. J Anaesthesiol Clin Pharmacol 2019;35:242-7.

10. Bösel J, Gandor F, Harms C, Synowitz M, Harms U, Djoufack PC, et al. Neuroprotective effects of atorvastatin against glutamateinduced excitotoxicity in primary cortical neurones. J Neurochem 2005;92:1386-98.

11. Dormuth CR, Hemmelgarn BR, Paterson JM, James MT, Teare GF, Raymond CB, et al.; Canadian Network for Observational Drug Effect Studies. Use of high potency statins and rates of admission for acute kidney injury: multicenter, retrospective observational analysis of administrative databases. BMJ 2013;346: f880.

12. Hippisley-Cox J, Coupland C. Unintended effects of statins in men and women in England and Wales: population based cohort study using the QResearch database. BMJ 2010;340:c2197.

13. Zhen-Han L, Rui S, Dan C, Xiao-Li Z, Qing-Chen W, Bo F. Perioperative statin administration with decreased risk of postoperative atrial fibrillation, but not acute kidney injury or myocardial infarction: a meta-analysis. Sci Rep 2017;7:10091.

14. Putzu A, de Carvalho E Silva CMPD, de Almeida JP, Belletti A, Cassina T, Landoni G, et al. Perioperative statin therapy in cardiac and non-cardiac surgery: a systematic review and meta-analysis of randomized controlled trials. Ann Intensive Care 2018;8: 95.

15. Ortega-Loubon C, Fernández-Molina M, Carrascal-Hinojal Y, Fulquet-Carreras E. Cardiac surgery-associated acute kidney injury. Ann Card Anaesth 2016;19:687-98.

16. Hulin A, Hego A, Lancellotti P, Oury C. Advances in pathophysiology of calcific aortic valve disease propose novel molecular therapeutic targets. Front Cardiovasc Med 2018;5:21.

17. Dahabreh IJ, Sheldrick RC, Paulus JK, Chung M, Varvarigou V, Jafri H, et al. Do observational studies using propensity score methods agree with randomized trials? A systematic comparison of studies on acute coronary syndromes. Eur Heart J 2012;33: 1893-901. 